
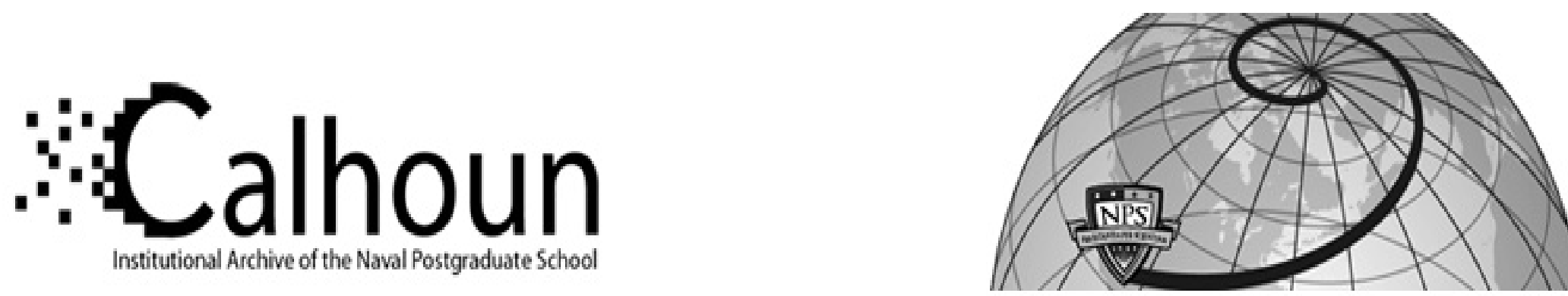

Calhoun: The NPS Institutional Archive DSpace Repository

Adaptive Architectures for Command and

Control: Toward An Empirical Evaluation of Organizational Congruence and Adaptation

Hutchins, Susan G.; Kemple, William G.; Kleinman, David L.; Hocevar, Susan P.; Diedrich, Frederick J.; Entin, Elliot E.

Hutchins, S. G., Kemple, W. G., Diedrich, F. J., Entin, E. E., MacMillan, J. and Serfaty, D. (2003). Presentation to the 71st Military Operations Research Society Symposium. Marine Corps Base Quantico, VA. 10-12 June, 2003. https://hdl.handle.net/10945/37939

This publication is a work of the U.S. Government as defined in Title 17, United States Code, Section 101. Copyright protection is not available for this work in the United States.

Downloaded from NPS Archive: Calhoun

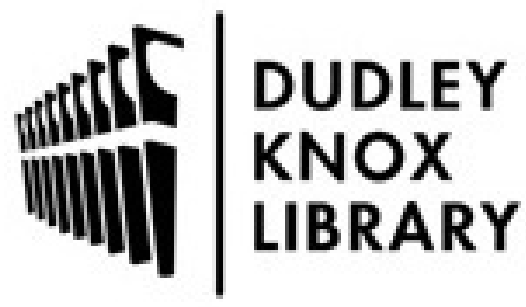

http://www.nps.edu/library
Calhoun is the Naval Postgraduate School's public access digital repository for research materials and institutional publications created by the NPS community. Calhoun is named for Professor of Mathematics Guy K. Calhoun, NPS's first appointed -- and published -- scholarly author.

Dudley Knox Library / Naval Postgraduate School 411 Dyer Road / 1 University Circle Monterey, California USA 93943 


\title{
Adaptive Architectures for Command and Control: Toward An Empirical Evaluation of Organizational Congruence and Adaptation
}

\author{
Frederick J. Diedrich ${ }^{1 *}$ \\ Susan P. Hocevar ${ }^{2}$ \\ Elliot E. Entin ${ }^{1}$ \\ Susan G. Hutchins ${ }^{3}$ \\ William G. Kemple ${ }^{3}$ \\ David L. Kleinman ${ }^{3}$ \\ ${ }^{1}$ Aptima, Inc. \\ 12 Gill St., Suite 1400 \\ Woburn, MA 01801 \\ (781) 935-3966 \\ diedrich@aptima.com; entin@aptima.com \\ ${ }^{2}$ Graduate School of Business and Public Policy \\ Naval Postgraduate School \\ 555 Dyer Road \\ Monterey, CA 93943 \\ (831) 656-2249 \\ shocevar@nps.navy.mil \\ ${ }^{3}$ Graduate School of Operations and Information Sciences \\ Naval Postgraduate School \\ 589 Dyer Road \\ Monterey, CA 93943 \\ (831) 656-3768; (831) 656-3309; (831) 656-4148 \\ shutchins@nps.navy.mil; kemple@nps.navy.mil; dlkleinm@nps.navy.mil
}

April 19, 2002

*Denotes author to contact.

This paper is submitted for consideration for the 2002 CCRTS track on C2 Experimentation. 


\title{
Adaptive Architectures for Command and Control: Toward An Empirical Evaluation of Organizational Congruence and Adaptation*
}

\author{
Frederick J. Diedrich ${ }^{1}$ \\ Susan P. Hocevar ${ }^{2}$ \\ Elliot E. Entin ${ }^{1}$ \\ Susan G. Hutchins ${ }^{3}$ \\ William G. Kemple ${ }^{3}$ \\ David L. Kleinman ${ }^{3}$ \\ ${ }^{1}$ Aptima ${ }^{\circledR}$, Inc. \\ 12 Gill St., Suite 1400 \\ Woburn, MA 01801 \\ ${ }^{2}$ Graduate School of Business and Public Policy \\ Naval Postgraduate School \\ 555 Dyer Road \\ Monterey, CA 93943 \\ ${ }^{3}$ Graduate School of Operations and Information Sciences \\ Naval Postgraduate School \\ 589 Dyer Road \\ Monterey, CA 93943
}

\begin{abstract}
How do teams cope with a misalignment between their organizational structures and mission requirements? Through a series of empirical and modeling efforts, our long-term goal is to understand the nature of organizational congruence, and to predict and measure the effects of a lack of congruence on the behaviors of organizations as they strive to adapt. In this paper, we present a series of lessons learned based on a pilot experiment in which we explored the performance of two organizations (functional and divisional) performing a single mission, which in this case, was not designed to favor a particular organization. The lessons learned here suggest a variety of empirical strategies to further our investigations, including measures of performance, rigorous attention to team and mission definitions, and precise planning of training structure. Our findings suggest that each of these factors has the potential to profoundly influence the results, reflecting the multiple factors that shape team performance.
\end{abstract}

\section{Introduction}

For the past several years, the Adaptive Architectures for Command and Control (A2C2) research team has examined the concept of organizational "congruence." This theory proposes that organizational effectiveness can be mediated when characteristics like

\footnotetext{
* The research reported here was sponsored by the Office of Naval Research, Contract No. N00014-99-C-0255, under the direction of Gerald Malecki. We thank Jean MacMillan and Daniel Serfaty for their assistance.
} 
organizational structure are designed to fit the requirements of a mission or environment (e.g., Donaldson, 2001; Van de Ven \& Drazin, 1985). This view suggests that when organizational structure is out of "alignment," quality of performance should be reduced, and if significant, this misalignment may drive organizational adaptation.

Some previous A2C2 efforts have examined ways to measure "fit" or "alignment" between structure and task requirements (e.g., Levchuk, Meirina, Levchuk, Pattipati, \& Kleinman, 2001). Building on this research, our goal is to understand the processes that underlie performance as teams attempt to cope with and adapt to misalignment. Toward this end, the research reported here focuses on a pilot experiment designed to explore the factors that affect the performance of teams operating in different structural organizations. We present a series of lessons learned that offer insight into the methodological implications of the processes at work that affect the investigation of organizational congruence and adaptation.

\subsection{Toward Empirical Evaluations of Congruence and Adaptation}

Over the next year, the A2C2 research team will conduct an experiment designed to explore the processes that characterize performance when teams are faced with misalignment between mission environments and organizational structures. More specifically, the focus of the experiment will be on the use of several modeling techniques (e.g., Carley \& Lee, 1998; Handley, Zaidi, \& Levis, 1999; Levchuk, Pattipati, \& Kleinman, 1998) to understand the nature of the congruence or "fit" between an organizational structure and mission, and to predict and measure the effects of a lack of congruence on the behaviors of the organization as it carries out its mission. The reasoning behind this approach is that when the structure of an organization becomes too "incongruent" with its mission, the organization will "feel the pain" and may (or may not) be motivated to adapt. By identifying the behaviors of organizations coping with incongruence, we hope to understand how they function so that we can subsequently induce on-line structural adaptation (changes in team organization). Consequently, the ultimate goal of the upcoming empirical work is an improved understanding of what incongruence looks like "in action" so that we can properly study whether and how incongruence leads to structural adaptation.

Our approach is to define two disparate organizational structures and design two missions (scenarios) that exploit the differences in these two structures. Thus, the first mission scenario will be "tuned" to organization 1 through a high degree of congruence, and will also be "mismatched" (i.e., exhibit low congruence) with organization 2. The reverse will be necessary for the second scenario. Building on previous work (Hutchins, Kleinman, Hocevar, Kemple, \& Porter, 2001), the two organizational structures that we will explore are commonly referred to as functional and divisional. In this work, the functional structure will be organized such that each participant will specialize in one aspect of the mission such as strike using assets that are distributed across multiple platforms (ships). In contrast, in the divisional structure, each participant will have control over a multifunctional platform that to a large extent will be able to process a variety of functional tasks such as air, surface, and subsurface threats. The two mission scenarios will be designed, theoretically, to favor either the divisional or functional architectures. 
However, before directly embarking on this experiment, we conducted a pilot experiment designed to better elucidate the properties of the missions and organizations necessary to meet our goals. In short, given the web of variables that influence team performance, the nature of the contextual factors that might affect congruence and adaptation is not obvious. This means that definition of the organizations and the missions is non-trivial, as are the methodological subtleties that could affect the results. Accordingly, the focus of this paper is on a pilot experiment in which we explored the performance of two organizations (functional and divisional) performing a single mission, which in this case, was not designed a priori to favor a particular organization. Below we outline the design of this pilot experiment and then present the results from this experiment in the context of lessons learned that will inform the design of subsequent work on organizational congruence and adaptation both within and beyond the $\mathrm{A} 2 \mathrm{C} 2$ program.

\section{Method}

\subsection{Participants}

Forty-two officers attending the Naval Postgraduate School in Monterey, CA, served as participants. Most of the officers were 03 or 04 and several services as well as foreign militaries were represented. Participants were organized into seven teams of six individuals each. Informed consent was obtained for all participants.

\subsection{Apparatus}

Participants engaged in a simulation of a mission involving six geographically dispersed commanders in control of assets including six major platforms: An aircraft carrier, a guided missile cruiser, two guided missile destroyers, a guided missile frigate, and an attack submarine. The platforms each had a variety of weapons with specified capabilities, and some had assets such as aircraft and helicopters. The simulation was implemented in the Distributed Dynamic Decision-making (DDD) environment. The DDD is a distributed realtime simulation environment that supports a variety synthetic team tasks. An example of the simulation display is shown in Figure 1.

\subsection{Procedure}

Participants began the experiment by learning how to control the various assets and how to use the various functions imbedded in the DDD simulation. This "buttonology" training lasted for approximately two hours (including simulation time and briefing time). Next, they conducted training in one organizational structure (functional or divisional) on variants of the mission scenario. This training lasted for approximately 60 minutes and was followed by an approximately 40-minute testing period in the actual mission scenario (the test period lasted a total of two hours including briefing and debriefing). The participants then came back a few days later to conduct training in the second organizational structure (60 minutes) followed by testing on the actual mission scenario (approximately 40 minutes in the scenario, two hours total). Thus, organizational structure was manipulated as a repeated measures factor that was 
counterbalanced across teams: Half of the teams started in divisional followed by functional and half started in functional followed by divisional.

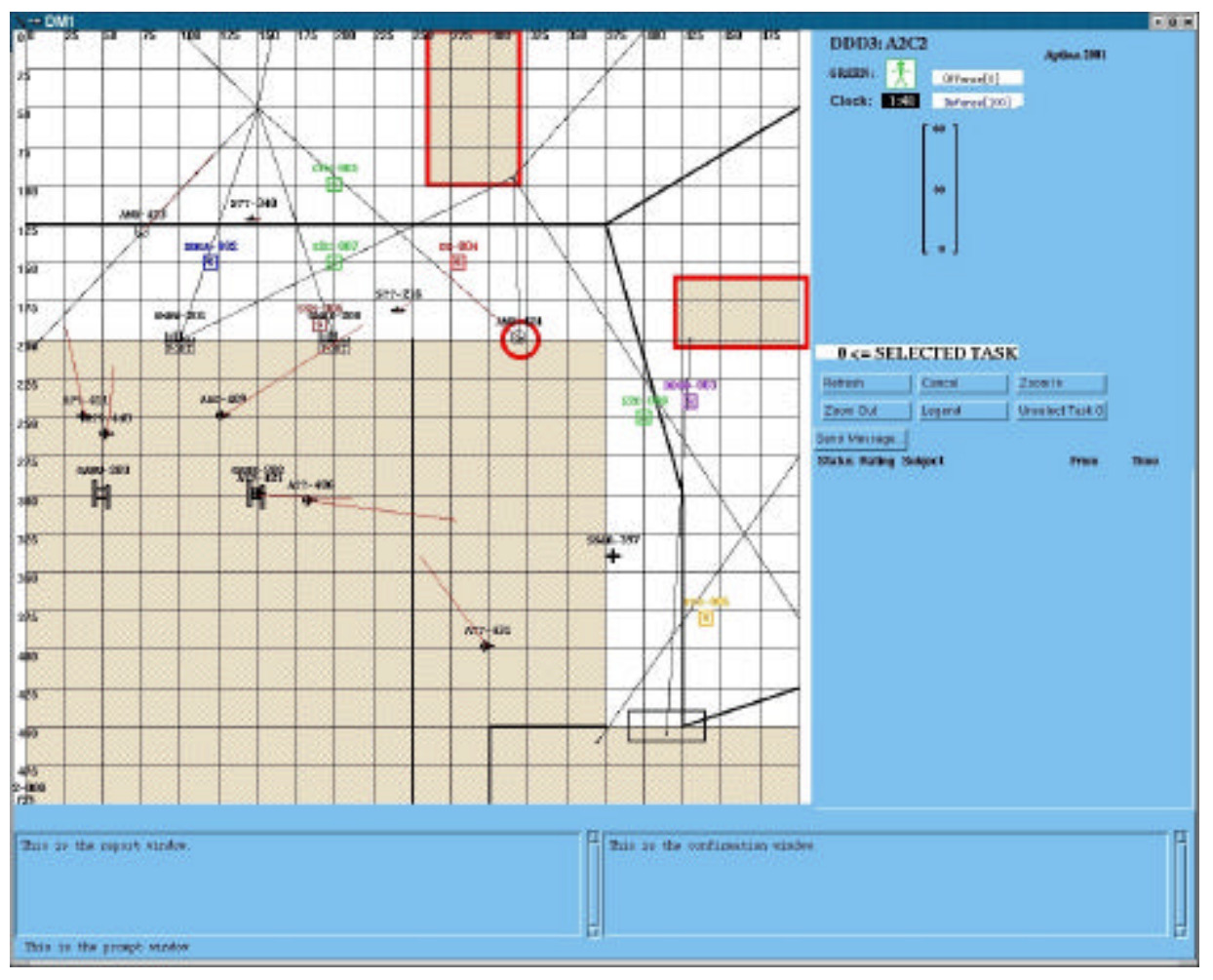

Figure 1. The DDD simulation display. The white areas represent water, the colored areas represent land (friendly areas outlined in bold), and the various icons represent friendly and hostile assets of different types.

More specifically, in the functional organizational structure, a participant charged with one aspect of the mission, such as air warfare, "owned" (had direct control of) the assets necessary to do that part of the mission even if those assets were on various platforms. Each of the six players had primary control of one of the following areas: strike, air warfare, ballistic missile defense, surveillance/search and rescue, surface warfare or undersea warfare. In contrast, in the divisional organizational structure, players had direct control over all assets on one multifunctional platform: A carrier (strike, air warfare, search and rescue), a guided missile cruiser (strike, ballistic missile defense, surveillance, surface warfare, undersea warfare), a guided missile destroyer (strike, ballistic missile defense, surveillance, surface warfare), a second guided missile destroyer (Strike, ballistic missile defense, surveillance, search and rescue, surface warfare), a guided missile frigate (surveillance, surface warfare, undersea warfare, search and rescue), and an attack submarine (strike, undersea warfare). Each of the platforms were located in a geographically distinct region, with some overlap of range such that multiple players could access the same targets in certain areas.

The mission involved preparing the battlespace for the arrival of follow-on forces by engaging hostile assets perceived as immediate threats (aircraft, patrol boats, destroyers, and submarines). Simultaneously, players were charged with destroying an enemy air base and 
an enemy naval base that were heavily guarded by surface-to-air missile (SAM) sites. In addition, players had to defend neighboring foreign friendly areas from SCUD missile attacks. Critically, the mission environment was significantly characterized by a variety of time-critical tasks (e.g., SCUD missile launchers, coastal defense launchers, search and rescue) that required immediate response. Likewise, many of these tasks required coordination between assets (e.g., a surveillance sensor to locate a target and an asset with which to destroy it) that could be controlled by one or more players. Note that the area of operation also contained neutral parties and hostile assets that did not directly engage friendly forces, and were therefore deemed to be low of the list of priorities as specified by the rules of engagement and commander's intent.

\section{Results and Discussion}

The primary purposes of this investigation were to: 1) Pilot test the methodologies used in the experiment (e.g., operationalization of the two organizational structures; training requirements); and 2) To collect preliminary data on the processes that underlie performance for these organizations coping with this particular mission. Below, we present our findings in the context of lessons learned that will inform the design of subsequent work.

\subsection{Measures of Performance}

Consideration of the performance of the teams indicated that rather than performance being superior for one organizational structure over another, performance depended on the types of tasks to which the teams were exposed. For instance, Figure 2 shows performance measured as the number of attacks attempted divided by the number of tasks arrived (present). This measure is a proportion that indicates how successful the teams were in terms of their ability to process the tasks that were present and that needed to be processed (i.e., these measures exclude items such as hostile aircraft that were not threatening and therefore did not need to be processed by the players). The primary strike targets included performance on the air base and naval base, which were identified in the commander's intent as being important strike targets. Time critical targets (launchers) included performance on SCUD launchers, coastal defense launchers, enemy destroyers, and enemy submarines. Each of these tasks threatened friendly assets or geographical areas if left unprocessed. Time critical targets (missiles) included SCUD missiles, coastal defense missiles, exocet missiles, and torpedoes fired by the "launchers." Thus, performance on time critical targets (missiles) represents how well the teams shot down missiles if they were unable to previously destroy the launchers shown in the time critical targets (launchers) columns. These data indicated that performance tended to be superior in the functional condition for the primary strike targets (paired two-tailed $\mathrm{t}(6)$ $=-0.81$, ns) and the launchers (paired two-tailed $\mathrm{t}(6)=-0.78$, ns), whereas the divisional teams outperformed the functional teams on the missiles (paired two-tailed t $(6)=2.85, \mathrm{p}<$ $0.05)$. Some caution should be taken in interpretation of these data because these trends were small and did not reach conventional levels of significance. However, we believe that these data are highly suggestive given the small $\mathrm{N}$ and pilot nature of the investigation. 


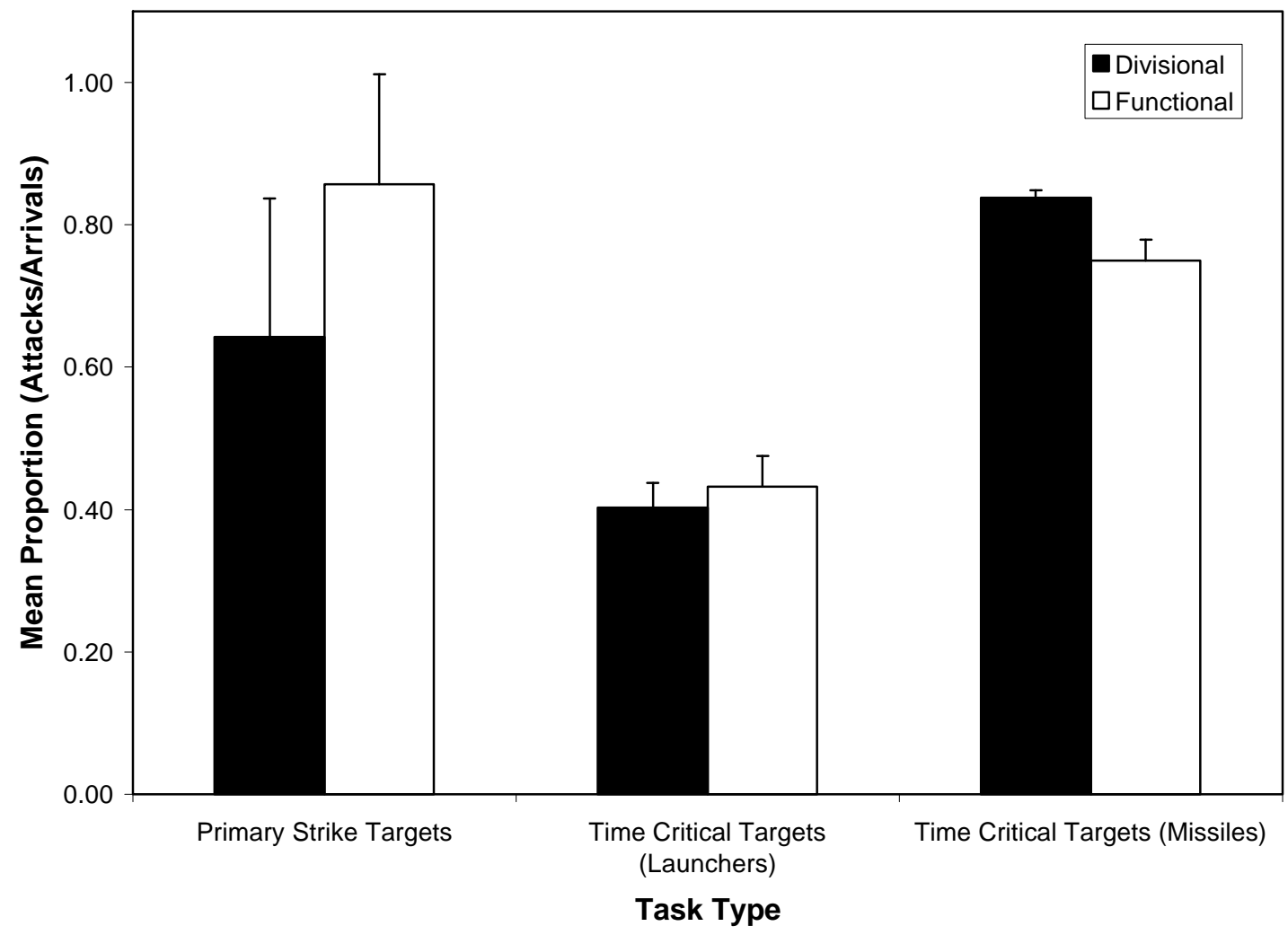

Figure 2. Performance of teams by task type, where performance is measured as the number of attacks attempted divided by the number of tasks arrived (present).

These data suggest that the functional teams tended to perform better on strike targets, but when threatened, the divisional teams were better prepared to deal with defensive actions. The defensive strength of the divisional teams may have been due to the spread of defensive assets across multiple players (e.g., 3 players had anti-ballistic missiles), whereas in the functional condition, defensive assets were concentrated in single players (e.g., one player had all of the anti-ballistic missiles). Since the SCUD missiles came in waves, it is likely that the single players responsible for ballistic missile defense in the functional condition were more easily overwhelmed. In contrast, in the functional condition performance on the primary strike targets may have tended to be superior in the functional case because one player could concentrate on strike and another could concentrate on surveillance. Both of these players were relatively free from other duties.

In fact, these data are consistent with observations from the players. Regarding mission capabilities, players remarked that:

- "In functional, because we had to rely on other players for much of our protection (instead of using self-defense), we could focus more on offensive mission responsibilities."

- "In divisional, it was easier to do self-defense without requiring the assistance of other players." 
- "Functional had better allocation of ISR because these assets were under the control of one individual."

- "The multi-function capability of divisional facilitated load-shedding if workload became too high, or providing back-up or assistance if others' workload became high."

- "Divisional had a greater focus on self-defense."

Combined with the performance measures, these data suggest that given the current scenario, the functional teams tended to have a slight advantage in offensive operations, while the divisional teams tended to have a slight advantage in defensive operations because of the way assets were allocated and the pattern of their use (over space and time) during the mission.

The lessons learned here are two: 1) Performance needs to be analyzed by consideration of the types of tasks to which the teams were exposed; 2) Different structural organizations may have superior capabilities in certain areas that can be exploited, thus facilitating the construction of scenarios that are tuned or mismatched to organizational proficiencies.

\subsection{Definition of Organizational Structures}

As noted above, in general the organizational structures were defined such that in the divisional organization players had control of a multifunctional platform, whereas in the functional organization players specialized in one area of the mission. However, this manipulation was not entirely "complete." For instance, in the divisional organization, each player did not have direct control of assets across all of the functional areas. Likewise, in the functional organization, although players had primary responsibility in one functional area, they could participate in modest ways in other areas as well. For example, in addition to anti-ballistic missiles, the player in the role of ballistic missile defense had assets (cruise missiles) that could be used to destroy items such as SCUD launchers. Yet, these cruise missiles could also be used for strike against items such as the air base. Similarly, although the player in the role of strike could use his cruise missiles to attack items such as the air base, these same assets could be used against SCUD launchers, thereby enabling some ballistic missile defense. This means that our organizations were not purely functional or divisional, but rather, they were somewhere on a continuum between the two extremes.

Moreover, asset distribution was not the only thing that influenced coordination requirements. For instance, due to overlap in the geographical boundaries between players (given asset ranges), players operating the divisional organization had to coordinate with each other over boundaries within the area of operations. This implies that while the functional condition may have forced coordination across functional areas (e.g., a sensor and a strike weapon might be needed to hit a target), the divisional condition forced coordination as players dealt with regional boundaries. Coordination was not present or absent, but instead, coordination requirements were different.

Player's comments reflected this difference in coordination requirements, and were often quite contradictory in appearance. For instance, regarding coordination, various players remarked that: 
- "In divisional, there was more autonomy for multi-function tasks, and thus, less need to coordinate."

- "In divisional, we needed to deconflict with other players capable of the same task."

- "In functional, coordination was more "contained" in that, for a given task, we only had to involve, typically, one other player to achieve a multifunctional requirement. This is in contrast with divisional where it was necessary to deconflict with several players who had multi-function capability."

- "Because functional required us to coordinate, it also motivated us to function more as a "team" than in divisional where we operated more autonomously."

Note that in related points, several of the players also had contradictory remarks about how the organizational manipulation affected situational awareness:

- "The greater requirement for coordination in functional increased the situational awareness in comparison with divisional."

- "Divisional forced the players to continually scan all aspects of the battlespace for opportunities and to track contacts, thus increasing situational awareness."

- "Divisional gave each player a more limited geographic area of operation to focus on so situational awareness in the area of operation was stronger, but total situational awareness was weaker."

- "Because in functional players had reach across the entire battlespace, there was greater situational awareness, but only related to the particular functional capability."

In total, then, these data suggest that similar to coordination, situational awareness was not better or worse across organizations, but instead, situational awareness was different. Moreover, these data suggest that situational awareness is in fact very difficult to precisely define.

Collectively, these data suggest that the asset distribution across players and the demands of the mission will influence both how much and what type of coordination is necessary. This is a critical point for future development, for the "distance" between the functional and divisional organizations will impact the "distance" between the scenarios that are tuned to match the different structures. Since the goal is to define scenarios that selectively challenge or exploit weaknesses in the two structures, the structures need to be different enough to generate different scenarios. With only minor differences between scenarios and structures, teams will be likely to make adaptations that are not structural in nature. Thus, for our purposes, this distance between the organizations should be maximized to the extent possible (Figure 3).

The lessons learned here are two: 1) Tight definition of team structures is necessary, as it will likely directly affect the obtained results; and 2) Players coordinate across many dimensions. Team structure alone does not determine coordination requirements, but instead, coordination requirements are subtly determined by the organizational structure operating within a particular task (mission) domain. 


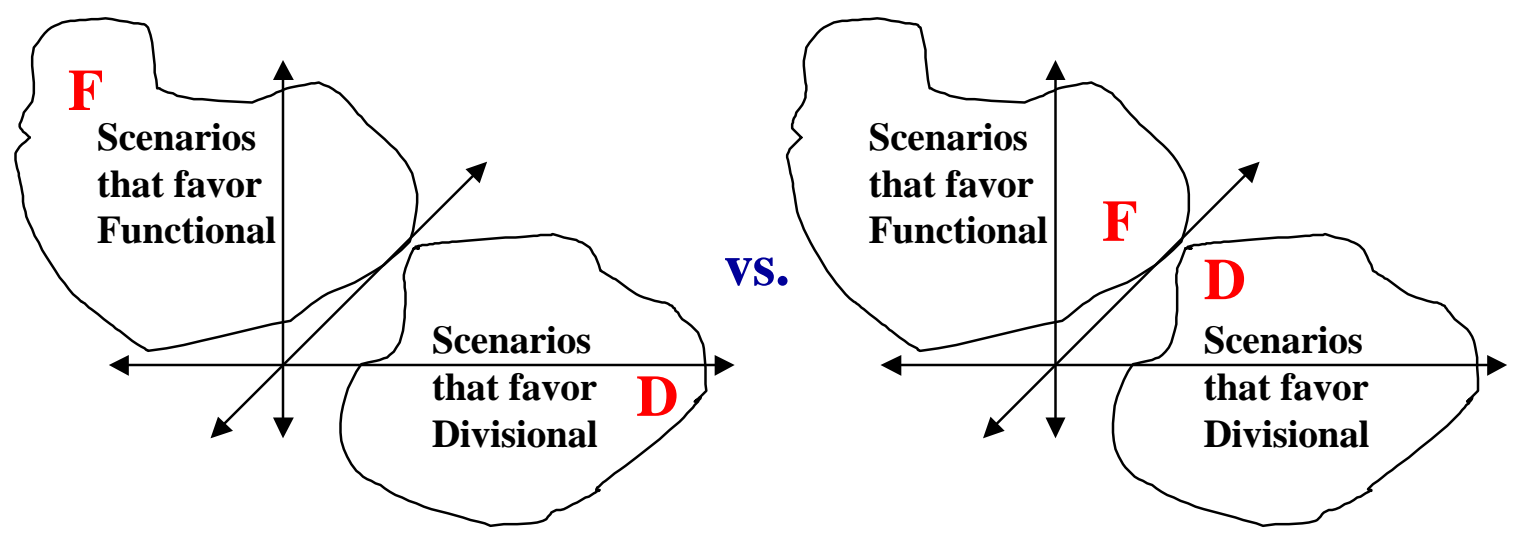

Figure 3. An abstract space representing definitions of scenarios that either fit functional (F) or divisional (D) organizational structures. On the left hand side of the figure, the F and D are spaced far apart, such that scenarios tuned to the organizations are substantially dissimilar. In contrast, on the right hand side of the figure, the $\mathrm{F}$ and $\mathrm{D}$ are spaced close together, such that scenarios tuned to the organizations are substantially similar. To maximize the need for structural adaptation, the structures need to be spaced far apart. Note that formal definition of these spaces depends on both modeling and empirical work.

\subsection{Structure of Training}

Two issues arise in a consideration of training: First, how much training should be provided? Second, how will the training influence subsequent performance? In the pilot experiment reported here, participants had an hour of training prior to testing in each organizational structure, and in addition, participants conducted "buttonology" training that was designed to familiarize them with the functional aspects of the DDD. During this "buttonology" training, participants launched a variety of assets from a platform under their control, similar to the divisional structure. However, players were also able to launch assets off of a different platform, similar to the functional structure.

The issue of amount of training is critical because it influences the stability of performance. Without substantial training, it is possible that observations will reflect how players learn to play the DDD rather than consistent differences between organizational and mission structures. However, with too much training, it is possible that between condition differences may disappear. For instance, some organizational theorists argue that teams find ways to compensate (e.g., leadership, planning, culture) for situations when structure is not congruent with the mission environment, such that they can perform as well as organizations that have a congruent structure (e.g., Donaldson, 2001). Indeed, one player remarked that: "Neither structure should be viewed as more capable than the other because, while each may have different limitations, these limitations can be overcome in different ways." These concerns suggest, therefore, that one needs to find a delicate balance between training too little and too much. Ideally, time-series based measures should be taken as "training" evolves so that one can measure how teams struggle and learn to adapt to their mission environments.

The issue of how training might affect performance is also critical, for the history of a team's activities may influence current performance. For instance, Moon, Hollenbeck, Ilgen, West, Ellis, Humphrey, and Porter (2000) reported that performance was higher for teams that 
transitioned from a functional to a divisional structure than for those that transitioned from a divisional to a functional structure. These data suggest that team performance depends on the history of prior activity, and that training may begin to build histories that constrain future performance.

Given, then, that history matters - that team behavior is path dependent - it is likely that much more is being learned during training than simply how to play the DDD, and that what is being learned is contributing profoundly to the results. Simply put, training needs to be carefully considered, for even slight biases in training (e.g., giving a team more experience in one organization than another, or the order of that training) may influence results.

Moreover, the effect of prior experience will likely interact with team structure and mission structure. Similar to the congruence effects noted above, the "distance" between team structures will influence how prior experience impacts current performance. Figure 4 once again shows a hypothetical space representing definitions of scenarios that either fit functional (F) or divisional (D). In the middle of the figure, the F and D are "spaced" moderately apart, whereas on the right hand side of the figure, the F and D are close together. It is possible that due to similarity, historical effects may be quite robust in the middle version, in which the scenarios are sufficiently distinct, yet similar enough, to interfere with each other. In contrast, when the scenarios are highly similar as on the right side, little interference from past experience may occur (i.e., little adaptation is necessary). Likewise, when the distance between the F and D is large as on the left side, historical effects may once again be small as the similarity decreases (i.e., little interference). In total, the magnitude, direction, and presence of order effects - and training effects - may depend on the "distance" between the scenarios (and the team structures) and what is learned. Of course, these effects depend on whether the structures and scenarios are differentiated along meaningful lines. In fact, the presence and direction of these effects may provide information about the structure of the space. An absence of a training or order effect is just as informative as the presence of such an effect.

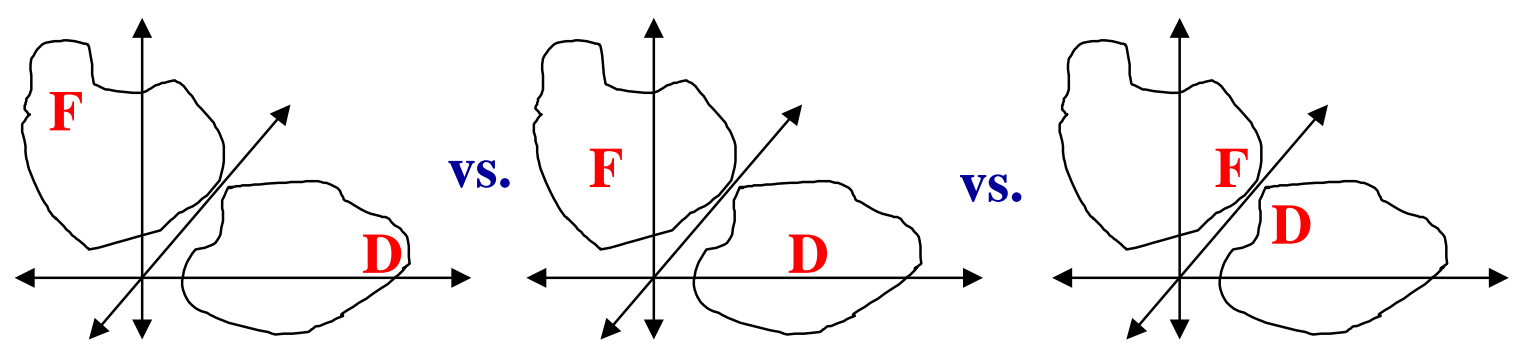

Figure 4. An abstract space representing definitions of scenarios that either fit functional (F) or divisional (D) organizational structures. The "distance" between the F and D will likely influence the observation of historical effects.

Consistent with these ideas, data from the pilot experiment suggest that the history of prior activity influenced performance. However, this influence seemed to depend on task type, consistent with the data shown above in Figure 2. Once again, Figure 5 shows performance measured as the number of attacks attempted divided by the number of tasks arrived (present) for the primary strike targets (top), time critical targets - launchers (middle), and time critical 
targets - missiles (bottom). Here, the data are shown by trial for teams who went from divisional to functional (solid line) and functional to divisional (dashed line). For the primary strike targets, performance in the functional organization tended to be superior regardless of trial. In contrast, for the missiles, performance in the divisional organization tended to be superior regardless of trial. However, in the case of the launchers, performance was superior across trials in the divisional to functional order. This means that divisional outperformed functional on trial 1, but that functional outperformed divisional on trial 2 . These data suggest that order effects may be present and that they can override apparent advantages for functional and divisional organizational structures. Note that some caution is need in interpreting these results, given that these effects represent only trends. However, given that these data are based on a low $\mathrm{N}$, we take these data as promising, for they suggest that history may matter and that these effects may depend on task type.

Here, the lessons-learned are three: 1) Time-series based measures of performance should be taken as training evolves in order to document how teams struggle to adapt to their missions;

2) Training needs to be carefully crafted so as to be of a proper amount and non-biased; and

3) The presence of order and training effects will depend on a variety of factors, including task type.

\section{Conclusions}

The results and insights gained from this pilot study provide valuable guidance as we move forward toward an empirical evaluation of organizational congruence and adaptation. The lessons learned suggest empirical strategies such as analysis by task type, rigorous attention to the consequences of team structure and mission definitions, and precise planning of the types and amounts of training. Each of these factors has the potential to profoundly influence the results, reflecting the multiple factors that shape team performance.

In particular, the preliminary results concerning task type suggest that in the context of the scenario studied in this pilot experiment, the functional organization was less proficient at interception of waves of enemy missiles. As noted above, this may reflect the fact that, for instance, anti-ballistic missiles rested in the hands of only a single player in the functional case. Importantly, this preliminary finding suggests a strategy for designing scenarios that are either congruent or incongruent with team structures: Functional organizations may be stressed by waves of attacks focused on one functional area (e.g., ballistic missile defense), whereas divisional organizations may be stressed by waves of attacks focused on one geographical area involving assets across several functional areas (i.e., thus stressing a single divisional region). The same concept - swamping of a particular player - can be accomplished in different ways. 

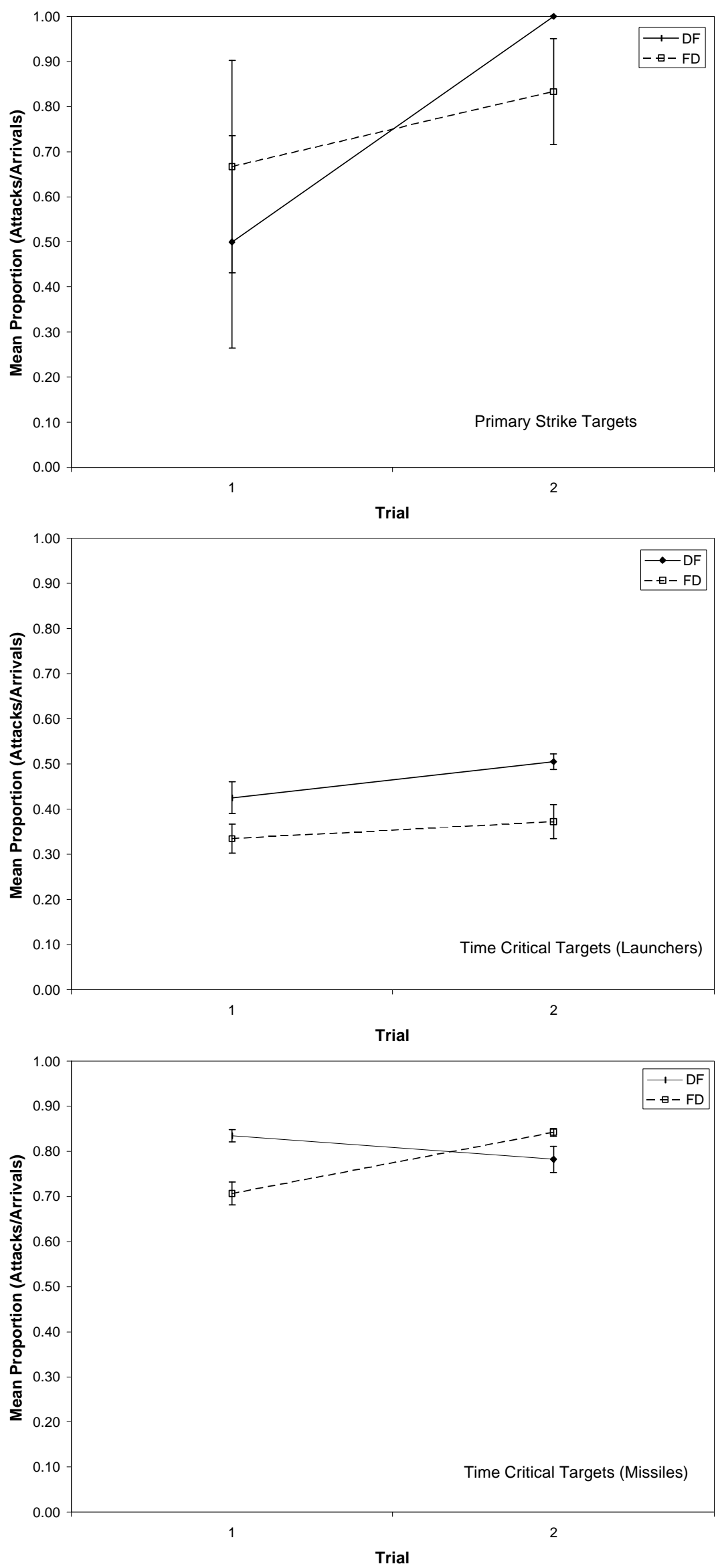

Figure 5. Performance by task type, where performance is measured as the number of attacks attempted divided by the number of tasks arrived (present). Data are shown by order, where divisional to functional is the solid line and functional to divisional is the dashed line. 
Ultimately, the findings reported where will help us as we study the nature of congruence between organizational structures and missions, and as we strive to predict and measure the effects of a lack of congruence on the behaviors of organizations as they carry out missions. By identifying the behaviors of organizations coping with incongruence - by understanding what incongruence looks like "in action"- we hope to understand how organizations function so that we can subsequently understand how to induce radical adaptation.

\section{References}

Carley, K.M. \& Lee, J. (1998). Dynamic Organizations: Organizational Adaptation in a Changing Environment. In J. Baum (Ed.), Advances in Strategic Management, Vol. 15, Disciplinary Roots of Strategic Management Research (pp. 269-297). JAI Press.

Donaldson, L. (2001). The Contingency Theory of Organizations. Thousand Oaks, CA: Sage.

Handley, H.A, Zaidi, Z.R., \& Levis, A.H (1999). The Use of Simulation Models in ModelDriven Experimentation. Proceedings of the 1999 Command and Control Research and Technology Symposium, 20-45.

Hutchins, S.G., Kleinman, D.L., Hocevar, S.P., Kemple, W.G., and Porter, G.R. (2001). Enablers of self-synchronization for Network-Centric Operations: Design of a complex command and control experiment. Proceedings of the $6^{\text {th }}$ International Command and Control Research and Technology Symposium. US Naval Academy, Annapolis, MD.

Levchuk, G.M., Meirina, C., Levchuk, Y.N., Pattipati, K.R., and Kleinman, D.L. (2001) Design and analysis of robust and adaptive organizations. Proceedings of the $6^{\text {th }}$ International Command and Control Research and Technology Symposium. US Naval Academy, Annapolis, MD.

Levchuk, Y., Pattipati, K.R., \& Kleinman, D. (1998). Designing adaptive organizations to process a complex mission: Algorithms and applications. Proceedings of the 1998 Command and Control Research and Technology Symposium, 11-32.

Moon, H., Hollenbeck, J., Ilgen, D., West, B., Ellis, A., Humphrey, S., Porter, A. (2000). Asymmetry in structure movement: Challenges on the road to adaptive organization structures. Proceedings of the Command and Control Research and Technology Symposium, Monterey, CA.

Van de Ven, A. H. and Drazin, R. (1985). "The concept of fit in contingency theory." In B.M. Staw and L.L. Cummings (Eds.) Research in Organizational Behavior, 7, 333-365. 